\title{
Discussion on the Integration of Management Accounting and Financial Accounting from the Perspective of IT
}

\author{
Wu Yuping \\ Liaoning Polytechnic Vocational College, Liaoning, Jinzhou, 121007, China
}

Keywords: management accounting; financial accounting; IT perspective; integration application

\begin{abstract}
With the continuous development of science and technology, computer technology has gradually emerged in various fields, and to a great extent, it has also promoted the development of the accounting industry in a better direction. From the perspective of IT, the integration of management accounting and financial accounting will be more closely. Therefore, how to use IT technology to realize this idea will be a very important topic. From the perspective of IT, this paper analyzes the integration of management accounting and financial accounting, and puts forward relevant opinions.
\end{abstract}

In recent years, with the continuous promotion of economic globalization, all enterprises are seeking development, the accounting industry is also seeking to change, the state has issued a clear policy to guide the direction. In 2014, the relevant policies issued by the state, how to promote the management of accounting information construction, how to make accounting. The integration of related business activities of the activity group has put forward more specific requirements. At the same time, China's enterprises in the continuous construction and development, also gradually realized the importance of the construction of information system, and applied it to the management of the enterprise, after a continuous attempt to improve, now the application of computer technology in financial accounting has begun to determine no small results, but There are still problems, such as some problems in management accounting, which have hindered the improvement of accounting quality. Accounting work will be affected by the working environment, and more work depends on whether the objective environment is changed or not. At the time of rapid economic development, the higher the status of the accounting, the higher the development of the IT technology, especially the rapid development of the technology. The computer information technology occupies a place in every field. It is the impact on all the traditional ways, and naturally it will have a considerable impact on the traditional accounting. The appearance of IT technology can help effectively. In practical work, the integration of management and information technology makes it an important part of accounting activities. Only when people realize the importance of IT technology and apply it, will improve the efficiency and quality of work. Under this premise, management accounting and financial accounting as the most important two parts of the accounting activities, with the change of the financial environment, changes are taking place, in the two parts constantly change the process of integration, the need for certain conditions and methods, this article is analyzed here.

\section{The relevant conditions for the integration of management accounting and financial accounting.}

The relevant theoretical requirements for the integration of management accounting and financial accounting[1].

As an important part of the enterprise development, the role of accounting can not be replaced, because the accounting department can clearly know the operation of the enterprise and the information of the decision-making. Accounting is mainly divided into financial accounting and management accounting. The former is mainly to provide financial information about the company's external stakeholders, such as the financial situation, operating results in recent years and changes in funds and so on. The latter is more inclined to serve the managers of enterprises and 
provide data support for decision makers, planner and managers. The work direction of financial accounting is to sort out the information that has been generated, and all the information provided is the data that has been generated. The focus of management accounting is to control future information and provide data support for enterprise development. The traditional accounting means can not meet the needs of the market under the situation of economic development. The traditional accounting activities can only make the enterprises secure themselves. The enterprises need not only manage the internal financial situation, but also have a clear judgment on the future development. These need strong data to support them. Therefore, the management accounting can predict the prospects of the development of the market economy, provide the decision-makers with the support of data, and evaluate the operation of the enterprise, and will be magnified and paid attention to. Therefore, in order to meet this requirement, it will naturally raise the requirements for the comprehensive ability of the financial related staff. It is necessary for the relevant staff in finance to take full account of the changes in the market economic activities, react and make financial decisions objectively and scientifically according to the characteristics of the development of their own enterprises. To ensure that these decisions can bring correct guidance to enterprises, reduce the risk of investment due to less familiarity with the changes in the future economic environment, improve the financial budget management ability within the enterprise, ensure that the enterprise funds can turn over and make effective investment, in the same time to protect the enterprises to go smoothly. Production and operation, increase the control of enterprise funds will be able to maximize the use of goods and funds, so that enterprises get the greatest economic benefits. The focus of the work of financial accounting is to consider how the enterprises carry out the production and operation, and to ensure the smooth production of the enterprises by the relevant accounting methods, which is an important guarantee for the actual production activities of the enterprises. And management accounting is based on the related data given by financial accounting, through the detailed processing, analysis, and finally forecast the future development direction of the enterprise, and according to these information to evaluate the feasibility, and finally summarize all the information for the enterprise managers to provide data support in decision-making, help. To help managers make decisions and provide feasible solutions, the management level of enterprises is improved. According to the above analysis, the management accounting and financial accounting are usually in the same data information when they work, so it is an inevitable trend to combine the two. The two are complementary to each other.

With the continuous development of computer technology, various industries use it to improve the efficiency of work. Under this environment, the accounting industry has also begun to use IT technology to assist the work. Not only light can improve the management level of accounting, but also ensure that the accounting information is more accurate and has a more reference value. There are many aspects involved in the production and operation of an enterprise, and a large amount of data will be generated in the daily operation. It is because the production of these data can help the enterprise to analyze whether the enterprise is developing in a good direction. Financial accounting and financial accounting can be analyzed according to these data. And this information is used again. The traditional accounting management model, in the calculation of these data because of more data, and more complex, too many aspects, so the efficiency of manual calculation is not high and there will be many problems, these problems are many, it also hinders the development of the enterprise, and computer technology. It can make up for this defect, and change this situation, not only the speed of calculation can be improved, but also the accuracy of the calculation can be improved, the working efficiency of the relevant staff is improved, and the production of the problem is to help the enterprise to save the cost. It is very heavy for the enterprise development. Yes.

The component of the accounting department can not be underestimated in the enterprise. It can affect the business situation of the enterprise. Therefore, the relevant staff in the management accounting work and the financial accounting work must be carried out by professional talents. There is a high requirement for the professional quality and moral cultivation of these staff, so most of the enterprises are very enthusiastic about the talent. For the enterprise itself, some staff should be trained to pay attention to it. Especially when the IT technology is gradually applied, the 
accounting related work needs not only the traditional accounting skills, but also the use of computer technology to complete the related work. Therefore, the enterprise management department should pay attention to this problem. The integration of management accounting and financial accounting needs professional talents to complete, introduce advanced talents to the company, train the rotten employees, through regular training, distance education, watch related knowledge lectures, and organize internal financial personnel. Knowledge competition, and so on, can play a role in the training of relevant staff, improve the professional quality of the staff, and improve the business ability of the staff. In particular, IT skills training should be strengthened to improve the use of IT technology, so that relevant staff can pay attention to this technology, and the application of IT technology will not manage the integration of accounting and financial accounting, fundamentally promote the improvement of the accounting level, and promote the development of enterprises in a healthy and good direction.

\section{The way to integrate management accounting and financial accounting from the perspective of IT.}

Now that science and technology are the first productive forces, the market is increasingly fierce today, all enterprises are seeking development on the road, all are seeking reform. Then the accounting department, as the core Department of the enterprise, must follow the changes in the market and make the management of accounting and financial accounting in the Perspective of IT. Business integration has become an inevitable trend, and enterprises must pay attention to it. Therefore, no matter the managers or the relevant personnel of the accounting department, we must pay more attention to this problem. It is necessary to have a correct recognition of the integration of management accounting and financial accounting, and dare to try the traditional accounting. It is not all denial, is to take the essence, to its dross, to the traditional accounting means to dare to innovate, to understand the importance of the use of IT technology, so that it can play a real role in the accounting system, so that the management accounting for the managers of the decision information can be accurate and scientific enough to make financial accounting in the daily life. The information provided by the battalion can be accurate and guaranteed, so that the two complement each other, jointly escort the development of enterprises, and enhance the economic efficiency of enterprises[6].

The enterprise wants to achieve good development, stand steadily in the market, not only because the market has the demand, but also needs the enterprise itself to have a sound mechanism to control, the internal and external combination can deal with the risks brought by the market change, the accounting department also needs strict system to control it, therefore, in the management meeting. When working with financial accounting, it is necessary to have internal control system. It is necessary for the relevant staff to work strictly in accordance with the relevant system, improve the ability of internal supervision and restraint, avoid unnecessary mistakes, and the mechanism of information early warning response. Only in this way can it be monitored. And solve accounting related staff in the operation process of violations. In particular, when computer technology is applied to various industries, the level of the technology is constantly improving. In contrast, the traditional means of accounting management can be seen to have more significant shortcomings. Then the application of IT technology in the accounting system can be used to strengthen the establishment of the internal management system. As well as sound, so as to help enterprises to achieve scientific distribution of human resources, so that it can be optimized to achieve the highest benefits. And to ensure that management accounting and financial accounting in the intertwined integration process can proceed smoothly, providing an important basis for the development of enterprises. The enterprise wants to carry on the reform, must take a long time, can be able to adapt gradually, so the current formulation of clear rules and regulations, behavior standard, can help the staff quickly into the role, the active completion of the work. Therefore, it is very important to improve the internal control mechanism of accounting management.

Through the application of computer technology to assist accounting and the integration of management accounting and financial accounting to make it possible to play a maximum efficiency, 
in order to achieve this goal, first of all, we should ask for the overall quality of the relevant staff, strengthen the professional knowledge and the training of computer technology. So that it can quickly grasp the technology, and in the work can be skilled in the use of a variety of software to complete the work, improve work efficiency. Secondly, the enterprise should invest more in IT technology, and use it in software development, so that IT technology can be used for its own use, design a software system that meets the needs of its own enterprise development, help the enterprise to complete the work better, make the traditional accounting management system get a qualitative leap, and will manage the management in the help of the IT technology. The effective integration of accounting and financial accounting can fundamentally improve work efficiency. Only advanced science and technology can promote the development of enterprises and conform to the law of market development[5].

\section{Conclusion}

As an important part of accounting, management accounting and financial accounting must be based on the mass information produced in the process of enterprise management and management. But there are obvious differences between the two. The management accounting is more inclined to predict the data information. The main function is the decision assistant function. Through the analysis of the massive information and data, it collate all kinds of information and put forward the data to help the enterprise manager to make some basis for making decision. The goal of enterprise development is that the financial accounting work is more inclined to the internal enterprise, mainly by means of financial accounting of the funds produced within the enterprise, in order to help the managers to improve the management of operating funds and ensure that the economic benefits are maximized. From the actual situation, financial accounting and management accounting are to serve the business and development of enterprises, whether it is cost accounting or decision goals in the future, both need to cooperate with each other, in order to reach the goal. With the rapid change of the market economy, the integration of management accounting and financial accounting on the basis of IT technology is the inevitable trend, because the integration of the two can not only improve the efficiency of accounting work, but also improve the economic efficiency of the enterprise fundamentally, and make the development space of the enterprise more space. Open. At the same time, the integrated development of accounting management has been promoted, the management of enterprise management is more standardized, the information level of enterprises is improved, and the comprehensive quality of the staff has been improved well. Therefore, the effective combination of management accounting and financial accounting in the perspective of IT technology is taken from all aspects. Whether it is from the current development of enterprises or the future trend, it is very necessary.

\section{References}

[1] Liao H, Xiang Y F. Discussion on the Transition Path from Traditional Financial Personnel to Management Accounting [J]. Sci-tech Innovation and Productivity, 2017.

[2] Mao W T, University Y. A discussion on the role of enterprise management accounting in promoting the fine management of enterprises [J]. Journal of Jiamusi Vocational Institute, 2016.

[3] Huang X. Discussion on the Problems of Accounting and Financial Management of Railway Infrastructure Construction [J]. Railway Economics Research, 2016.

[4] Huang N. Discussion on the Application of Cloud Accounting in Enterprise Accounting Informatization[C]// International Conference on Economics, Social Science, Arts, Education and Management Engineering. 2016.

[5] Jiang Y P. Discussion on Financial Accounting and Management of Enterprise Infrastructure Construction Engineering [J]. Management \& Technology of Sme, 2018.

[6] Zhang M S, Zhu M S. Discussion on the Construction of Management Accounting 
Informatization under the Background of qInternet $+\mathrm{q}[\mathrm{C}] / /$ International Symposium on Social Science. 2017.

A brief introduction to the author: Wu Yuping (1968.11--), female, Manchu, Jinzhou, Liaoning Province, undergraduate, associate professor, main research directions: higher vocational education, accounting 